\title{
Correlation Between Onco-suppressors PTEN and NM23 and Clinical Outcome in Patients With T1 Breast Cancer
}

\author{
LUCIANO IZZO $^{1}$, DANIELA MESSINEO ${ }^{2}$, PIERFRANCESCO DI CELLO ${ }^{3}$, \\ VIRGILIO NICOLANTI ${ }^{1}$, ANTONIO STERPETTI $^{1}$, SARA IZZO $^{4}$ and PAOLO IZZO ${ }^{1}$

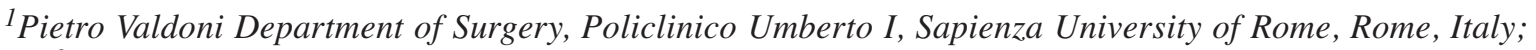 \\ ${ }^{2}$ Department of Radiological Sciences, Oncology and Pathology, Sapienza University, Rome, Italy; \\ ${ }^{3}$ UOC Chirurgia Generale Frosinone-Alatri presso ASL Frosinone, Frosinone, Italy; \\ ${ }^{4}$ Multidisciplinary Department of Medical-Surgical and Dental Specialties, \\ Plastic Surgery Unit, Luigi Vanvitelli University of Campania, Naples, Italy
}

\begin{abstract}
Background: The aim of the present work was to evaluate the prognostic significance in patients with $T 1$ breast cancer of tissue expression of the two oncosuppressors phosphatase and tensin homolog (PTEN) and non-metastatic clone 23 (NM23) as detected by immunohistochemistry. Materials and Methods: We prospectively analyzed 62 patients who underwent surgery for a T1 stage breast cancer. Expression of PTEN and NM23 was tested for correlation with clinical characteristics and clinical outcome. Results: Of the 62 patients considered for our study, 16 underwent mastectomy and 46 underwent conservative surgical treatment. The surgery was considered radical $(R O)$ in all cases described. PTEN and NM23 expression was higher in patients with no lymph node metastases and no recurrent cancer at a mean follow-up of 36 months (range $=6-48$ months). This correlation was more evident when both PTNE and NM23 expression were highly expressed $(p<0.0001)$. Conclusion: Low or lack of PTEN and NM23 immunohistochemical expression in cancer tissue is a risk factor for lymph node involvement and recurrent disease. It may represent a valid prognostic factor in planning therapy in patients who had surgery for T1 breast cancer.
\end{abstract}

The incidence of breast cancer has significant geographical variability. Survival rates are lower in developing countries. In the European Union, mortality is decreasing, with an annual

This article is freely accessible online.

Correspondence to: Professor Luciano Izzo, Dipartimento di Chirurgia P. Valdoni, Sapienza Università degli Studi di Roma, Via G.Tomasi di Lampedusa 9, 00144, Rome, Italy. E-mail: luciano.izzo@uniroma1.it

Key Words: PTEN, NM23, HER2, breast cancer. reduction of $2.1 \%$. One of the reasons for this trend is the increased prevalence of mammography screening (1). There is also an increasing prevalence of patients with a diagnosis of T1 breast cancer. Patients with T1 breast cancer represent an heterogeneous group with different clinical outcomes. Analysis of hormone receptors, proliferation indices, markers, and genomic analyses might allow several phenotypic characteristics of $\mathrm{T} 1$ breast cancer to be determined, allowing therapy to be adapted to the specific patient $(2,3)$.

Onco-suppressors represent a heterogeneous group with several functions, such as in cell apoptosis and interruption of the cell cycle in the case of irreparable DNA damage, inhibition of cell replication, and facilitation of cell contact inhibition. Phosphatase and tensin homolog (PTEN) gene is located on chromosome 10q23. PTEN encodes a lipid phosphatase of 403 amino acids that plays a key role in the regulation of the cell cycle and subsequent apoptosis mechanisms (4). PTEN gene mutations are associated with Cowden's syndrome, characterized by multiple hamartomata and a high risk of breast, endometrial and thyroid carcinomas. In breast cancer it has been observed that while PTEN gene mutations are uncommon (less than 5\%) (5), several immunohistochemical studies have shown that reduced expression of PTEN protein is present in 30-50\% of patients with breast cancer (6).

Included in the category of metastasis-suppressor genes is non-metastatic 23 clone (NM23). Its gene expression is reduced in murine highly metastatic melanoma cell lines compared to their non-metastatic counterparts. The NM23-H1 gene product has been proposed to be a kinase involved in synthesis of nucleic acids, glucose and some lipid derivatives.

The aim of the present work was to evaluate the prognostic significance of tumor tissue expression of PTEN and NM23 in patients with T1-stage tumors, as determined by immunohistochemistry. We tried to determine the correlation of tissue expression of PTEN and NM23 with 
other known prognostic factors such as axillary lymph node involvement, tumor size, histopathological grade, receptor status, and the clinical history of the patients.

\section{Materials and Methods}

Study design. We prospectively evaluated female patients who underwent surgery at our Department from February 2015 to February 2020 for T1 breast cancer detected by mammography screening (Figure 1). The characteristics of the tumor and the clinical outcome of the patients were correlated to the expression of PTEN and NM23 in the tumor tissue, detected by immunohistochemistry. The study was approved by the Ethical Committee of our University (Department approval 2014-516R). All patients gave written informed consent.

Surgery. All patients underwent sampling of axillary sentinel nodes. In the case of involvement of axillary lymph nodes, a complete axillary lymphadenectomy was performed. Quadrantectomy or mastectomy was performed according to the decision of the patients.

Inclusion criteria. Patients with a tumor diameter $<2 \mathrm{~cm}$ (T1), ductal infiltrating histotype and no clinical evidence of metastatic disease at diagnosis who underwent radical surgical treatment of cancer (R0).

Exclusion criteria. Patients with tumor diameter larger than $2 \mathrm{~cm}$; axillary lymph node enlargement at clinical examination; presence of local symptoms (pain, erythema); bilateral tumors.

Immunohistochemistry. The following antibodies were used for immunohistochemical analysis: anti-PTEN (monoclonal, 1:50 dilution; Spring Bioscience Corp, Pleasanton, CA, USA) and antiNM23 (monoclonal, prediluted; ScyTek, Logan, UT, USA).

The immunohistochemical study was carried out on 4- $\mu$ m-thick sections of tissue fixed in formalin and embedded in paraffin. The sections were collected on positively charged slides and placed in an oven for $5 \mathrm{~min}$ at $50^{\circ} \mathrm{C}$ and then they were dewaxed in xylol and rehydrated using an alcoholic series until they reached running water. The antigenic sites were highlighted by heat treatment using a microwave oven at $750 \mathrm{~W}$, for 3 cycles of $5 \mathrm{~min}$ each, in a TRIS/EDTA citrate buffer solution, at $\mathrm{pH} 7.8$ for both antibodies, followed by a cooling period of $20 \mathrm{~min}$ at room temperature. The endogenous peroxidases were then blocked with a 5-min bath in $3 \%$ hydrogen peroxide. After washing with distilled water, the sections were covered with diluted normal serum (UltraTEK HRP antipolivalent; SCYTEK), for $10 \mathrm{~min}$ and then incubated with $100 \mathrm{ml}$ of primary antibody for $30 \mathrm{~min}$ for anti-NM23 and $60 \mathrm{~min}$ for antiPTEN at room temperature. Each slide, after rinsing twice with phosphate-buffered saline (PBS) for 5 min each, was incubated with two/three drops of secondary biotylinated antibody (UltraTEK HRP anti-polyvalent; SCYTEK) and after rinsing with PBS was incubated for $10 \mathrm{~min}$ with two to three drops of serum containing the avidin/biotin complex (UltraTEK HRP anti-polyvalent; SCYTEK). After again rinsing with PBS, the sections were incubated for $5 \mathrm{~min}$ with chromogen substrate solution, diaminobenzidine (DAB, UltraTEK HRP anti-polivalent; SCYTEK) and finally were counterstained in hematoxylin for $10 \mathrm{~s}$, dehydrated in an increasing alcohol series, clarified in xylol and mounted in synthetic resin.
Table I. Characteristics of cases analyzed in this study.

\begin{tabular}{|c|c|}
\hline Characteristic & Value \\
\hline \multicolumn{2}{|l|}{ Age, years } \\
\hline Mean (range) & $57(30-85)$ \\
\hline \multicolumn{2}{|l|}{ Surgery, n (\%) } \\
\hline Quadrantectomy & $46(74.19 \%)$ \\
\hline Mastectomy & $16(25.80 \%)$ \\
\hline \multicolumn{2}{|l|}{ Adjuvant therapy, n (\%) } \\
\hline Total & $48(91.89 \%)$ \\
\hline Chemotherapy & $11(21.15 \%)$ \\
\hline Hormonotherapy & $22(42.30 \%)$ \\
\hline Chemo+hormonotherapy & $9(17.30 \%)$ \\
\hline Trastuzumab & $6(17.64 \%)$ \\
\hline \multicolumn{2}{|l|}{ Tumor size, n (\%) } \\
\hline T1a & $6(9.67 \%)$ \\
\hline T1b & $12(19.35 \%)$ \\
\hline T1c & $44(74.19 \%)$ \\
\hline \multicolumn{2}{|l|}{ Lymph nodes, n (\%) } \\
\hline $\mathrm{N}+$ & $13(21.97 \%)$ \\
\hline $\mathrm{N}-$ & $49(79.03 \%)$ \\
\hline \multicolumn{2}{|l|}{ Grading, n (\%) } \\
\hline 1 & $19(30.64 \%)$ \\
\hline 2 & $32(51.62 \%)$ \\
\hline 3 & $11(17.74 \%)$ \\
\hline \multicolumn{2}{|l|}{ Estrogen receptor, n (\%) } \\
\hline Positive & $41(66.12 \%)$ \\
\hline Negative & $21(33.88 \%)$ \\
\hline \multicolumn{2}{|l|}{ Progesterone receptor, n (\%) } \\
\hline Positive & $40(64.51 \%)$ \\
\hline Negative & $22(35.48 \%)$ \\
\hline \multicolumn{2}{|l|}{ HER2, n (\%)* } \\
\hline Positive & $20(32.26 \%)$ \\
\hline Negative & $42(67.74 \%)$ \\
\hline \multicolumn{2}{|l|}{ Receptor status overall, n (\%) } \\
\hline Triple-negative & $6(11.53 \%)$ \\
\hline \multicolumn{2}{|c|}{ Status at end of study follow-up } \\
\hline Alive & $55(88.7 \%)$ \\
\hline Disease-free & $49(89.09 \%)$ \\
\hline With recurrence & $6(10.91 \%)$ \\
\hline Lost to follow-up & $7(11.3 \%)$ \\
\hline
\end{tabular}

HER2: Human epidermal growth factor receptor 2. *As evaluated by immunohistochemistry.

The expression of PTEN was measured as follows: Score 0: absent; score 1: average positivity; score 2: intense positivity (normal).

The expression of NM23 was measured as follows: Score 0-3: no or slight expression ( $<5 \%$ of cells); score $4-6$ : moderate expression (5-75\% of cells); score 7-9: intense expression ( $>75 \%$ of cells; normal). The immunohistochemistry score was assessed independently by two examiners who did not know the histological and clinical characteristics of the patients. There was no discordance between the two examiners.

Correlation of PTEN and NM23 expression and histological and clinical parameters. The clinicopathological parameters correlated with PTEN and NM23 expression were: i) T1 stage: T1mic, microinvasion $<0.1 \mathrm{~cm}$ in maximum size; T1a, between $0.1 \mathrm{~cm}$ 

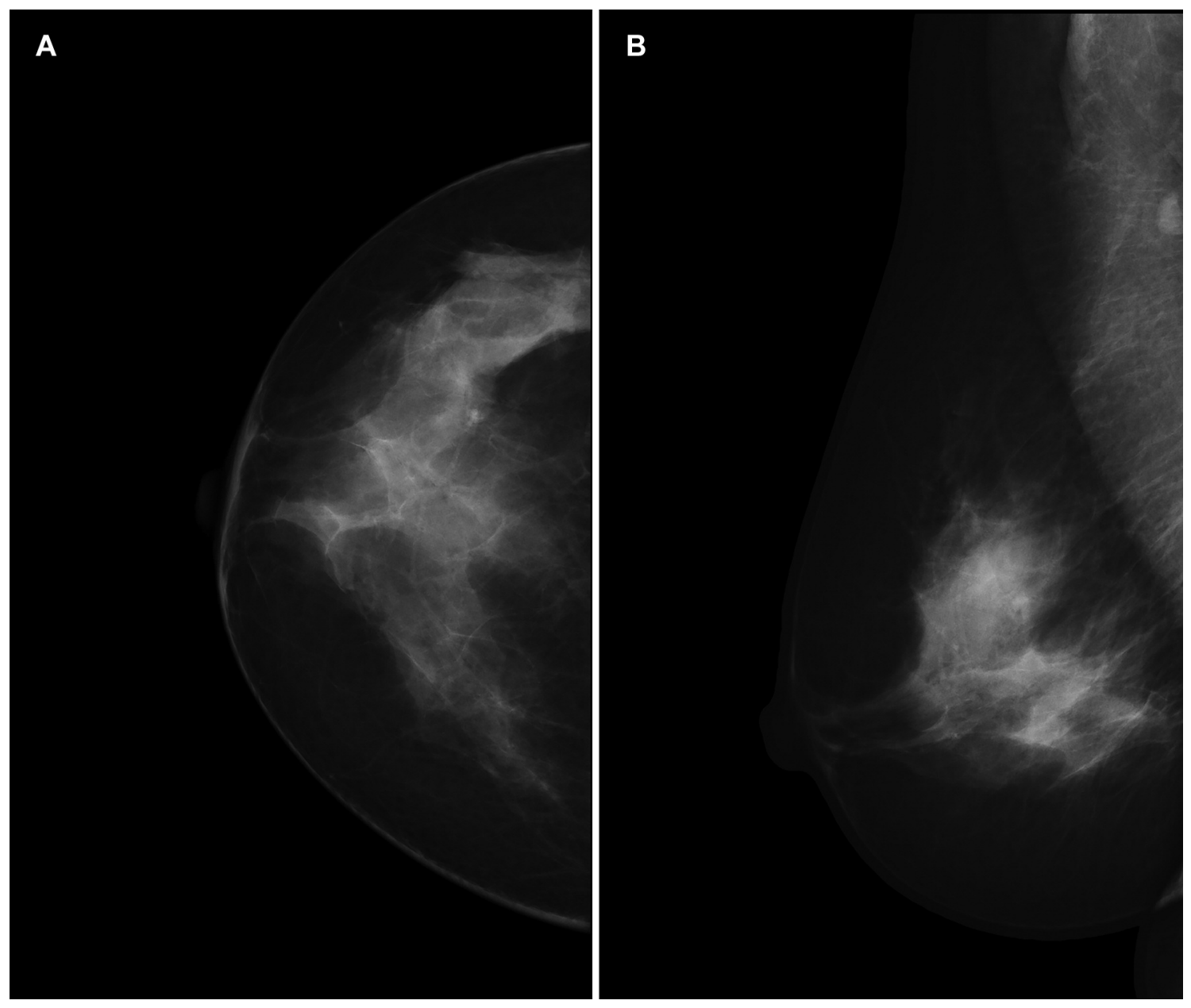

Figure 1. Screening mammography in a 56-year-old showing glandular distortion in the right breast, T1C, with lymph node involvement. A: Craniocaudal view. B: Mediolateral oblique view.

and $0.5 \mathrm{~cm}$; T1 b, between $0.6 \mathrm{~cm}$ and $1 \mathrm{~cm}$; and T1c, between 1.1 $\mathrm{cm}$ and $2 \mathrm{~cm}$, according to the seventh edition of the American Joint Committee on Cancer (2019) (7); ii) Histopathological degree; iii) Status of hormonal receptors and human epidermal growth factor receptor 2 (HER2); iv) Presence of lymph node metastases at final histology; v) Locoregional recurrence or distant metastasis.

Differences were analyzed by Fisher test, chi-squared test and multivariate analysis

\section{Results}

Sixty-two patients were included in the study. The age of the patients ranged from 30 to 85 years (median of 57 years). Follow-up ranged from 4 to 48 months (mean=36 months). Sixteen patients underwent mastectomy and 46 underwent conservative surgical treatment. Surgery was considered radical (R0) in all cases. Table I shows the clinical characteristics of the patients.
PTEN immunohistochemical expression was normal (score 2) in 32 patients $(51.61 \%$ ), and reduced or absent (score $0-1$ ) in 30 (48.39\%). NM23 was overexpressed (score $7-9)$ in 34 patients $(54.84 \%)$; in 19 cases $(30.64 \%)$ the immunoreactivity was medium (score 4-6), and in nine (14.52\%) it was low or absent (score 0-3). At a mean followup of 36 months, 55 patients were alive and free of disease, while seven were lost to follow-up. PTEN expression was reduced or absent in 18 cases and normal in 27; NM23 was of high intensity in 28 cases, medium intensity in 12 and low intensity or absent in four. There was no statistically significant difference between severity of the disease and positivity for PTEN and NM23. Immunohistochemistry showed higher levels of PTEN and NM23 expression in patients with no lymph node involvement and no evidence of recurrent disease, without reaching a statistically significant $p$-Value $(p>0.99)$. However, the simultaneous evidence of high levels of PTEN and NM23 was statistically 




Figure 2. Distribution of scores for immunohistochemical expression of phosphatase and tensin homolog (PTEN) according to lymph node involvement. $N+$ : With involvement. $N-$ : without involvement.

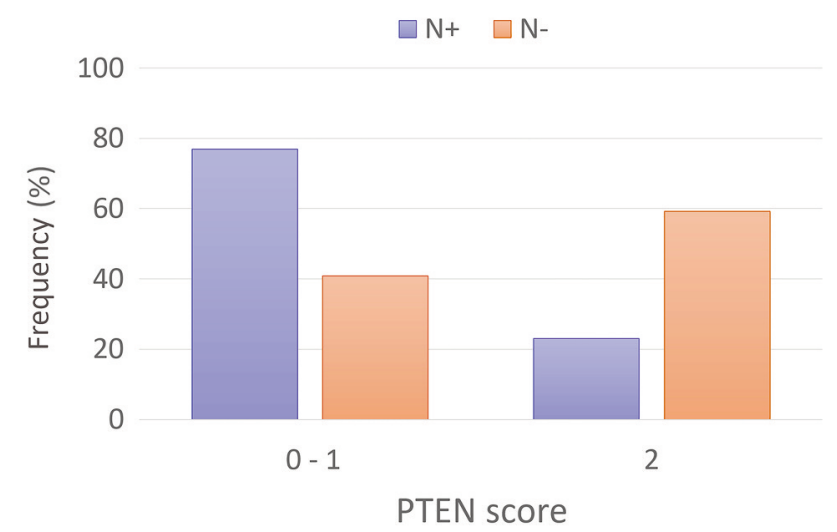

Figure 3. Distribution of scores for immunohistochemical expression of non-metastatic clone 23 (NM23) according to lymph node involvement. $\mathrm{N+}$ : With involvement. $N-$ : without involvement.

correlated with less lymph node involvement in both univariate and multivariate analyses $(p<0.01)$ (Figures 2-5).

Six patients $(13.97 \%)$ developed a local relapse of the disease. Six patients were diagnosed with axillary lymph node metastases; in four of them PTEN and NM23 were both absent (score 0). In the other two patients, NM23 and PTEN were both expressed but at medium-low intensity (score 6 and 1 respectively) $(p<0.01)$.

\section{Discussion}

Several reports have already analyzed the immunohistochemical expression of PTEN and NM23: these studies analyzed the

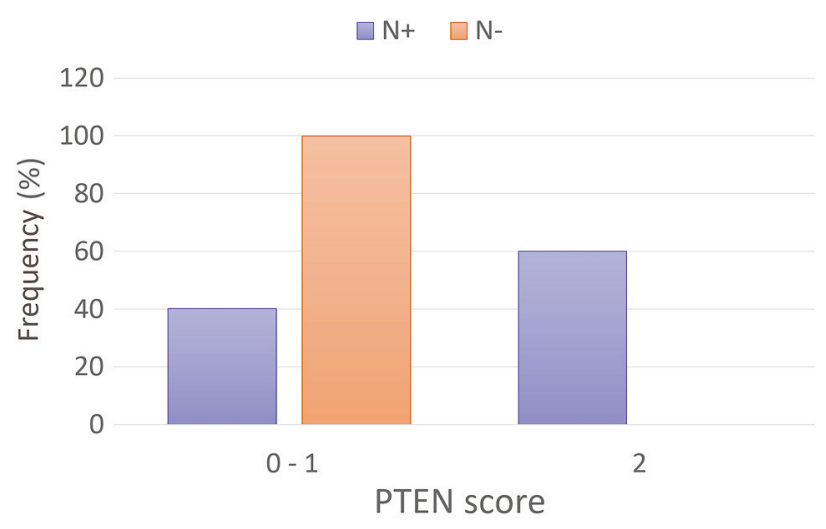

Figure 4. Distribution of scores for immunohistochemical expression of phosphatase and tensin homolog (PTEN) at the follow-up of 36 months according to lymph node involvement. $N+$ : With involvement. $N-$ : without involvement.

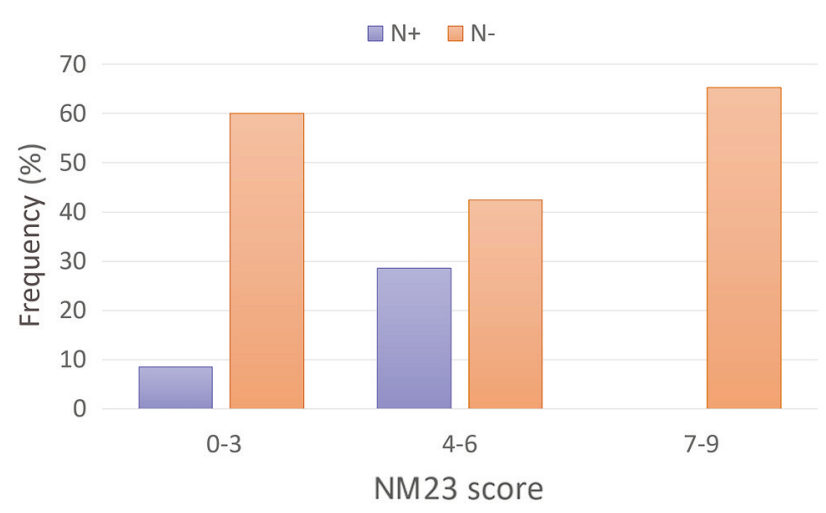

Figure 5. Distribution of scores for immunohistochemical expression of non-metastatic clone 23 (NM23) in patients without recurrent disease during follow-up. according to lymph node involvement. N+: With involvement. $N-$ : without involvement.

correlation of each marker separately, including mainly patients with breast tumors in advanced stage. In these studies, a significant association between reduced PTEN expression and lymph node metastases was evident $(13,16,17)$. A significant correlation between PTEN loss and negativity for estrogen (ER) and progesterone (PR) receptors has been documented (8). Knowles et al. (9) found that the loss of PTEN was significantly associated $(p<0.001)$ with the basal-like phenotype $\left(\mathrm{ER}^{-}, \mathrm{PR}^{-}\right.$, $\mathrm{HER}^{-}, \mathrm{CK} 5 / 6^{+}$and $\mathrm{EGFR}^{+}, \mathrm{CK} 5 / 6^{+}$or $\mathrm{EGFR}^{+}$), while a high expression was more often evident in patients with the luminal A phenotype $\left(\mathrm{ER}^{+}\right.$and $\mathrm{PR}^{+}, \mathrm{ER}^{+}$or $\left.\mathrm{PR}^{+}, \mathrm{HER} 2^{-}\right)(9,10)$.

Loss of PTEN has also been associated with resistance to tamoxifen and trastuzumab (10). The expression of NM23 has 
been evaluated predominantly on metastatic cell lines. Bal et al. studied the immunohistochemical expression of NM23 in several benign and malignant epithelial lesions of the breast. They found a progressive down-regulation of NM23 as the tumor progressed to a metastatic stage (11). This inverse correlation between loss of NM23 and the presence of lymph node metastases has also been demonstrated by others: Tokunaga et al. $(p<0.01)(12)$, Heimann et al. $(13)(p<0.05)$, and Royds et al. $(p<0.01)(14)$.

The objective of our study was to determine the correlation between immunohistochemical expression of PTEN and NM23 and clinical outcome in patients with early stage breast cancer (stage T1). Sixty percent of patients with breast cancer and axillary lymph node involvement were found to be PTEN-negative $(p<0.001)$ with a recurrence rate of $57 \%$ within 5 years $(8,15-18)$.

Reduced or absent immunohistochemical expression of PTEN in our study was found in $48.39 \%$ out of 62 cases of T1 invasive breast cancer: 13 patients had lymph node metastases at diagnosis and 69\% showed reduced or absent immunohistochemical expression of PTEN. Four patients with lymph node involvement and immunohistochemistry negative for PTEN developed a local relapse of the disease within 5 years of surgery. These differences did not reach statistical significance $(p>0.99)$ due to the small number of patients.

Regarding lymph node status, out of 32 patients with N0 disease, none presented a complete loss of NM23 - it was normally expressed in 22 cases (66\%) and moderately) in 10 cases $(34 \%)$. On the other hand, in out of 14 patients with $\mathrm{N}+$ disease, NM23 was absent or weakly expressed in eight cases $(60 \%)$ and normal only in one case. Charpin et al. showed NM23 expression $>3 \%$ to be correlated with improved metastasis-free survival in patients with positive and those with negative lymph nodes (19). Heimann et al. documented a disease-free survival of $91 \%$ at 5, 10 and 15 years in patients with normal expression of NM23 and $70 \%$ in those with low expression $(p<0.008)(13)$.

While PTEN gene mutations are uncommon in patients with breast cancer (less than 5\%) (5), several immunohistochemical studies have shown that reduced expression of the PTEN protein is present in $30-50 \%$ of such patients (6). Most studies have included patients with advanced breast cancer. In these patients, there is the possibility that the expression of PTEN and NM23 may be related to other intervening factors, which may influence the level of expression of the two oncosuppressors. Phenotypic expression of these two oncosuppressors is correlated to tumor microenvironmental factors, including cell death-related acidosis, inflammation and cytokine release, and the factors favoring phenotypic expression are difficult to determine in advanced tumors (9). In early-stage breast cancer, the expression of PTEN and NM23 is conceptually less related to the surrounding microenvironment.
We found a significant correlation of the simultaneous reduced expression of PTEN and NM23 with lymph node involvement and possibility of recurrent disease.

\section{Conclusion}

The introduction of new prognostic factors into clinical practice may improve the results of personalized therapy in patients with T1 breast cancer. On the basis of the results of or study we can conclude that in patients with $\mathrm{T} 1$ breast cancer, the simultaneously reduced expression of PTEN and NM23 in cancer tissue might be an important prognostic factor predicting the development of a recurrence of the disease.

\section{Conflicts of Interest}

The Authors declare that they have no conflicts of interest.

\section{Authors' Contributions}

Luciano Izzo supervised the research design, interpretation of the data and contributed to editing the article. Daniela Messineo participated in the data acquisition and contributed to editing the article. Pierfrancesco Di Cello, participated in the data acquisition. Virgilio Nicolanti participated in the data acquisition. Antonio Sterpetti contributed to writing and editing the article. Sara Izzo interpreted the data, and contributed to writing and editing the article. Paolo Izzo mainly acquired and analyzed the data and wrote the draft and designed the research. All Authors participated in critical revision of the article for important intellectual content.

\section{References}

1 Sancho-Garnier $\mathrm{H}$ and Colonna M: Breast cancer epidemiology. Presse Med 48(10): 1076-1084, 2019. PMID: 31706896. DOI: 10.1016/j.lpm.2019.09.022X

2 Li X, Wang Q, Fu L, Liu M and Yu X: Expression of PTEN, p53 and EGFR in the molecular subtypes of breast carcinoma and the correlation among them. Zhong Nan Da Xue Xue Bao Yi Xue Ban 40(9): 973-978, 2015. PMID: 26408616. DOI: 10.11817/j.issn.1672-7347.2015.09.005

3 Stankovic T, Milinkovic V, Bankovic J, Dinic J, Tanic N, Dramicanin $\mathrm{T}$ and Tanic N: Comparative analyses of individual and multiple alterations of p53, PTEN and p16 in non-small cell lung carcinoma, glioma and breast carcinoma samples. Biomed Pharmacother 68(5): 521-526, 2014. PMID: 24767865. DOI: 10.1016/j.biopha.2014.03.014

4 Shoman N, Klassen S, McFadden A, Bickis MG, Torlakovic E and Chibbar R: Reduced PTEN expression predicts relapse in patients with breast carcinoma treated by tamoxifen. Mod Pathol 18(2): 250-259, 2005. PMID: 15475931. DOI: 10.1038/ modpathol.3800296

5 Gonzalez-Angulo AM, Ferrer-Lozano J, Stemke-Hale K, Sahin A, Liu SJ.Barrera JA, Burgues O, Lluch AM, Chen H, Hortobagyi GN, Mills GB and Meric-Bernstam F: PI3K pathway mutations and PTEN levels in primary and metastatic breast cancer. Mol Cancer Ther 10(6): 1093-1101, 2011. PMID: 21490305. DOI: $10.1158 / 1535-7163 . M C T-10-1089$ 
6 Li S, She Y, Wang M, Yang J, Lv M, Li P, Chen Z and Yang J: Loss of PTEN expression in breast cancer: association with clinicopathological characteristics and prognosis. Oncotarget 8(19): 32043-32054, 2017. PMID: 28410191. DOI: 10.18632/ oncotarget.16761

7 O'Cearbhaill R, Gannon JM, Prichard RS, Walshe JM, McDermott E and Quinn CM: The American Joint Commission Cancer 8th Edition prognostic stage including Oncotype DX ${ }^{\circledR}$ Recurrence Score: Impact on staging of early breast cancer. Pathobiology 86(23): 77-82, 2019. PMID: 30347405. DOI: 10.1159/000493363

8 Shi W, Zhang X, Pintilie M, Ma N, Miller N, Banerjee D, Tsao MS, Mak T, Fyles A and Liu FF: Dysregulated PTEN-PKB and negative receptor status in human breast cancer. Int $\mathrm{J}$ Cancer 104(2): 195-203, 2003. PMID: 12569575. DOI: 10.1002/ijc.10909

9 López-Knowles E, O’Toole SA, McNeil CM, Millar EK, Qiu MR, Crea P, Daly RJ, Musgrove EA and Sutherland RL: PI3K pathway activation in breast cancer is associated with the basal-like phenotype and cancer-specific mortality. Int J Cancer 126(5): 1121-1131, 2010. PMID: 19685490. DOI: 10.1002/ijc.24831

10 Razis E, Bobos M, Kotoula V, Eleftheraki AG, HP Kalofonos, Pavlakis K, Papakostas P, Aravantinos G, Rigakos G, Efstratiou I, Petraki K, Bafaloukos D, Kostopoulos I, Pectasides D, Kalogeras KT, Skarlos D and Fountzilas G: Evaluation of the association of PIK3CA mutations and PTEN loss with efficacy of trastuzumab therapy in metastatic breast cancer. Breast Cancer Res Treat 128(2): 447-456, 2011. PMID: 21594665. DOI: $10.1007 / \mathrm{s} 10549-011-1572-5$

11 Bal A, Joshi K, Logasundaram R, Radotra BD and Singh R: Expression of NM23 in the spectrum of pre-invasive, invasive and metastatic breast lesions. Diagn Pathol 3: 23, 2008. PMID: 18510781. DOI: $10.1186 / 1746-1596-3-23$

12 Tokunaga Y, Urano T, Furukawa K, Kondo H, Kanematsu T and Shiku H: Reduced expression of NM23-H1, but not of NM23$\mathrm{H} 2$, is concordant with the frequency of lymph-node metastasis of human breast cancer. Int J Cancer 55(1): 66-71, 1993. PMID: 8102131. DOI: $10.1002 /$ ijc. 2910550113

13 Heimann R, Ferguson DJ and Hellman S: The relationship between NM23, angiogenesis, and the metastatic proclivity of node-negative breast cancer. Cancer Res 58(13): 2766-2771, 1998. PMID: 9661889.
14 Royds JA, Stephenson TJ, Rees RC, Shorthouse AJ and Silcocks PB: NM32 protein expression in ductal in situ and invasive human breast carcinoma. J Natl Cancer Inst 85(9): 727-731, 1993. PMID: 8386774. DOI: 10.1093/jnci/85.9.727

15 Depowski PL, Rosenthal SI and Ross JS: Loss of expression of the PTEN gene protein product is associated with poor outcome in breast cancer. Mod Pathol 14(7): 672-676, 2001. DOI: 10.1038/modpathol.3880371

16 Perren A, Weng LP, Boag AH, Ziebold U, Thakore K, Dahia PL, Komminoth P, Lees JA, Mulligan LM, Mutter GL and Eng C: Immunohistochemical evidence of loss of PTEN expression in primary ductal adenocarcinomas of the breast. Am J Pathol 155(4): 1253-1260, 1999. PMID: 10514407. DOI: 10.1016/S00029440(10)65227-3

17 Tsutsui S, Inoue H, Yasuda K, Suzuki K, Higashi H, Era S and Mori M: Reduced expression of PTEN protein and its prognostic implications in invasive ductal carcinoma of the breast. Oncology 68(4-6): 398-404, 2005. PMID: 16020969. DOI: $10.1159 / 000086981$

18 Zhu L, Loo WT and Louis WC: PTEN and VEGF: Possible predictors for sentinel lymph node micro-metastasis in breast cancer. Biomed Pharmacother 61(9): 558-561, 2007. PMID: 17919877. DOI: 10.1016/j.biopha.2007.08.015

19 Charpin C, Garcia S, Bonnier P, Martini F, Andrac L, Horschowski $\mathrm{N}$, Lavaut $\mathrm{MN}$ and Allasia C: Prognostic significance of NM23/NDPK expression in breast carcinoma, assessed on 10-year follow-up by automated and quantitative immunocytochemical assays. J Pathol 184(4): 401-407, 1998. PMID: 9664906. DOI: $10.1002 /($ S ICI ) 1096-9896(199804)1 84:4<401::AID PATH1220>3.0.CO;2-U

Received September 2, 2020

Revised October 15, 2020

Accepted October 16, 2020 